\title{
Estimating Unconfined Compressive Strength of Sedimentary Rocks in United Arab Emirates from Point Load Strength Index
}

\author{
Hussain Salah, Maher Omar, Abdallah Shanableh \\ Department of Civil and Environmental Engineering, University of Sharjah, Sharjah, UAE \\ Email: hqasem@sharjah.ac.ae, momar@sharjah.ac.ae, shanableh@sharjah.ac.ae
}

Received February 2014

\begin{abstract}
In this paper, three rock types including Sandstone, Mudstone, and Crystalline Gypsum were part of a laboratory study conducted to develop a dataset for predicting the unconfined compressive strength of UAE intact sedimentary rock specimens. Four hundred nineteen rock samples from various areas along the coastal region of the UAE were collected and tested for the development of this dataset and evaluation of models. From the statistical analysis of the data, regression equations were established among rock parameters and correlations were expressed and compared by the ones proposed in literature.
\end{abstract}

\section{Keywords}

Sedimentary Rocks, United Arab Emirates, Unconfined Compressive Strength, Point Load Strength Index, Regression Analysis

\section{Introduction}

A closer look at the development projects and construction boom that occurred in the last decade in the United Arab Emirates (UAE) gives thoughtful considerations about the construction of such major projects. In every construction project, geotechnical investigations are carried out to determine how the components of the project that interact with the soil and rock should proceed. Geotechnical investigations vary in complexity and prices; some of them require days of sophisticated work, complex procedures to be followed and fortunes of money to be spent. Therefore, geotechnical engineers thought about devising easier, less sophisticated and cheaper ways to estimate results of some important geotechnical parameters. Estimation of such parameters is also needed to overcome sampling and handling problems. Estimation of parameters is typically done through generating empirical correlations that simplify estimation of the values of parameters with considerations to safety and efficiency.

One of the most important rock parameters is the unconfined compressive strength (UCS). It is used widely in 
rock classifications like Rock Mass Rating (RMR), analysis and design of rock related structures. Here, special sample preparation is involved. In the case of sedimentary rocks, UCS testing becomes harder due to the fact that the recovered rocks are sometimes of such geometric parameters that they are not allowed by the code to have the test performed on them, or some rocks fail in the preparation stage before performing the UCS test. Therefore, the need of a way to determine this important parameter arises. Moreover, due to the lack of information on local rocks, the main purpose of this work is to generate empirical relations between UCS of sedimentary rocks of UAE and the point load strength index $\mathrm{I}_{\mathrm{s}(50)}$ of these samples. For the sake of fulfillment of this study, 419 samples were collected from different places in the UAE, especially the coastal zone, to statistically relate UCS with point load strength index.

\section{Previous Investigations}

An interesting study was conducted by G. Tsiambaos and N. Sabatakakis [1] on the strength of intact sedimentary rocks, which aimed to find correlations between point load strength index $\mathrm{I}_{\mathrm{s}(50)}$ with UCS and Hoek-Brown material constant $\left(\mathrm{m}_{\mathrm{i}}\right)$. In their study, sedimentary rocks from Greece where used. They compared their work to previous work of Bieniawski and the International Society of Rock Mechanics (ISRM). They concluded that the relation between point load index and UCS could be presented through three different models. The first linear model is shown in Figure 1; gave an acceptable value of $\mathrm{R}^{2}$ of 0.75 and their result was similar to the one found by Bieniawski and the ISRM. The power model was the second one also shown in Figure $\mathbf{1}$ as the dashed curve. This model showed a better relationship as $\mathrm{R}^{2}$ was 0.82 . The categorized linear model shown in Figure 2 was

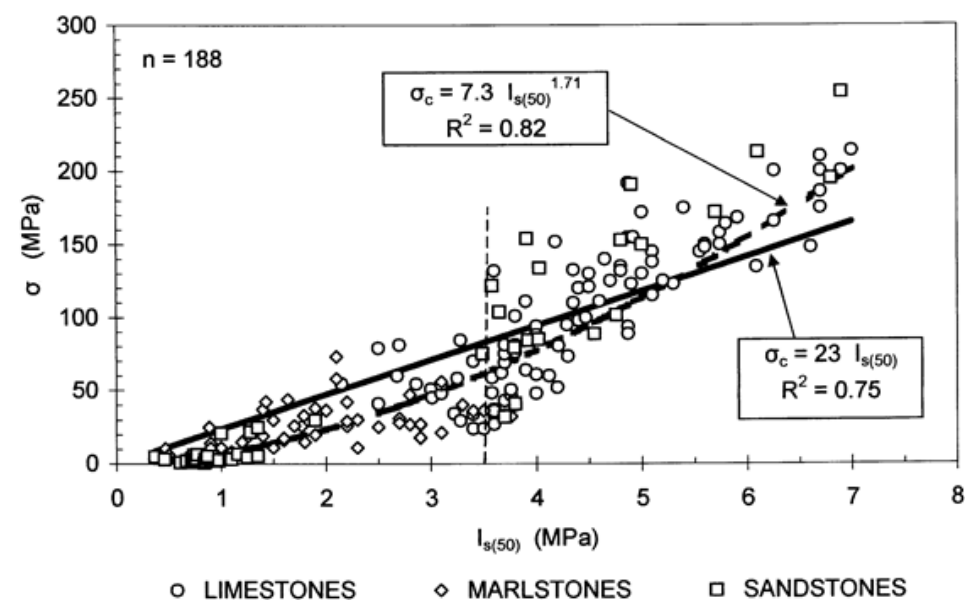

Figure 1. Linear and power models found [1].

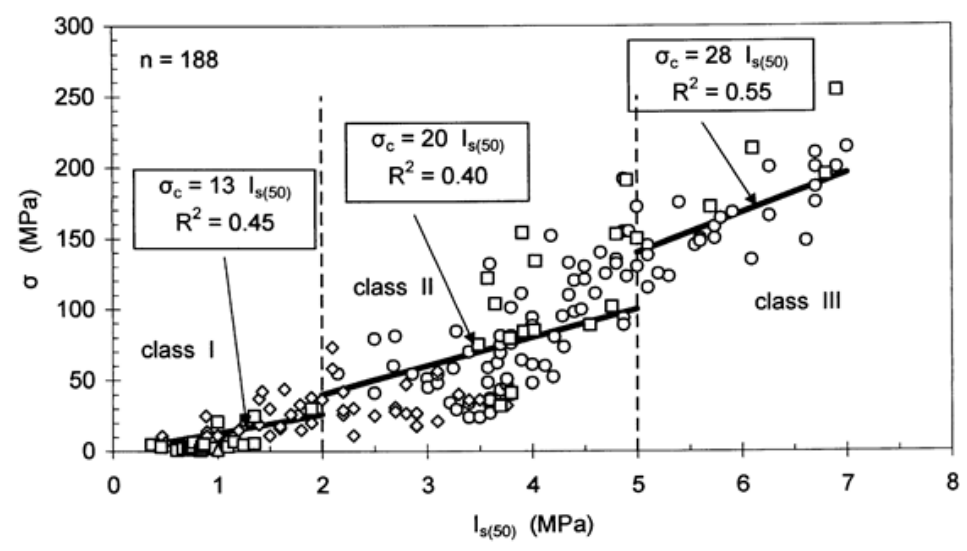

○ LIMESTONES $\diamond$ MARLSTONES $\square$ SANDSTONES

Figure 2. Categorized correlation [1]. 
the third one. They have observed that the point load index could be categorized into three different classes (I, II and III). For each class a conversion factor was assigned to multiply with the point load strength index value in order to get the UCS value.

The ASTM D-5731-08 presented a correlation between UCS and $\mathrm{I}_{\mathrm{s}(50)}$ which is dependent on a site specific conversion factor (C) to multiply with the point load strength index value in order to get the UCS value. If no data about (C) was available, the code gives generalized values for (C) acquired from the ISRM suggested methods for determining point load strength. These values are given in Table 1.

Broch and Franklin [3] found out that for $50 \mathrm{~mm}$ diameter cores the uniaxial compressive strength is approximately equal to 24 times the point load index. They also developed a size correction chart so that core of various diameters could be used for strength determination. Another study by D'Andrea et al. [4] relating uniaxial compression and the point load tests on a variety of rocks. They found the following linear regression model to correlate the UCS and $\mathrm{I}_{\mathrm{s}(50)}$.

$$
q_{u}=16.3+15.3 I_{s(50)}
$$

\section{The UCS Test}

There are three types of compressive strength tests of rocks as defined by Jaegar et al. [5]; the first is the UCS where only the axial load is applied to a rock sample and no lateral loads of any type are applied, mathematically speaking $\left(\sigma_{1}>0, \sigma_{2}=\sigma_{3}=0\right)$; the second is the triaxial loading where not only axial loading is applied on the rock sample, but also equal lateral loading is applied on the other two dimensions, mathematically speaking $\left(\sigma_{1}>\right.$ $\sigma_{2}=\sigma_{3}$ ); the third is the true triaxial loading, similar to triaxial loading but the difference being that lateral loads are not equal, mathematically speaking $\left(\sigma_{1}>\sigma_{2}>\sigma_{3}\right)$. Figure 3 illustrates the different compression types: (a) Implies UCS, (b) implies triaxial loading and (c) implies true triaxial loading.

The UCS test is commonly used as an easy and less sophisticated among all three compression test types. Other tests are also needed if further understanding of rock failure in semi-natural cases is required. In general, rock triaxial and true triaxial are seldom performed in the UAE. Testing was performed in accordance with the American Society of Testing and Materials (ASTM) code number D2938-02 [6] requirements. Although this code was withdrawn in the year 2005 by the ASTM, the replacement code number ASTM-D7012-10 [7], which is the unconfined compressive strength (UCS) and modulus of elasticity (E) testing procedures, specifies that the details of the testing procedure is acquired from the withdrawn code and using it is recommended. The follow-

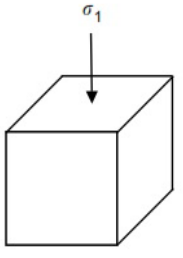

(a)

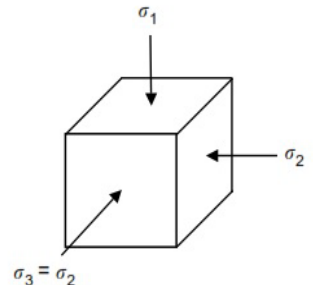

(b)

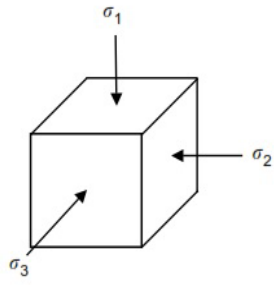

(c)

Figure 3. Different compression states of rocks [5].

Table 1. Generalized values of (C), [2].

\begin{tabular}{cc}
\hline Core Size (mm) & Generalized Value of $(\mathbf{C})$ \\
\hline 20 & 17.5 \\
30 & 19 \\
40 & 21 \\
50 & 23 \\
54 & 24 \\
60 & 24.5 \\
\hline
\end{tabular}


ing Equation (1) is used to determine the UCS, Where $\left(\mathrm{P}_{\mathrm{u}}\right)$ is the ultimate load and (d) is the sample's diameter:

$$
U C S=P_{u} /\left(0.785 d^{2}\right)
$$

\section{Point Load Test}

The ASTM-D5731-08 [8] code gave a clear justification for the use of the point load test. The code started its justification by giving statements about the time and money spent on performing a UCS test and recommended the use of simpler in-situ tests of which the point load test was one of them. The code also stated that this test can be used as an indexing method for rock classification. It is good to mention here that the diametral testing procedure was used for all cylindrical rock cores cut to perform this test. The point load strength index $\mathrm{I}_{\mathrm{s}(50)}$ is determined as per the following Equation (2), where $P_{u}$ is the failure load and $D_{e}$ is the effective diameter which is the core diameter for diametral test

$$
I_{s(50)}=\left(D_{e} / 50\right)^{0.45} P_{u} / D_{e}^{2}
$$

\section{Results and Discussion}

In this study, 419 rock samples were collected from various areas along the coastal region of the UAE. A statistical summary of the test results are shown in Table 2.

As many models can be identified, the power model was the best fit to describe the relation between UCS and $I_{s(50)}$ with an $R^{2}$ value of 0.68 as shown in Figure 4 for all rock types and strengths (AA). Another model of importance was the linear model; even though it gave lower $\mathrm{R}^{2}$ value of 0.63 but the equation generated is of big importance for comparison with the standardized equations for the determination of UCS. Other relationships developed for different soil types and strengths are summarized in Table 3 and some are shown in Figures 5-10.

To evaluate the capabilities of present proposed correlations, generated values were plotted versus measured values and compared with previous studies. Correlations developed by ASTM/ISRM, Tsiambaos and Sabatakakis [2] were selected for comparison and shown in Figure 11.

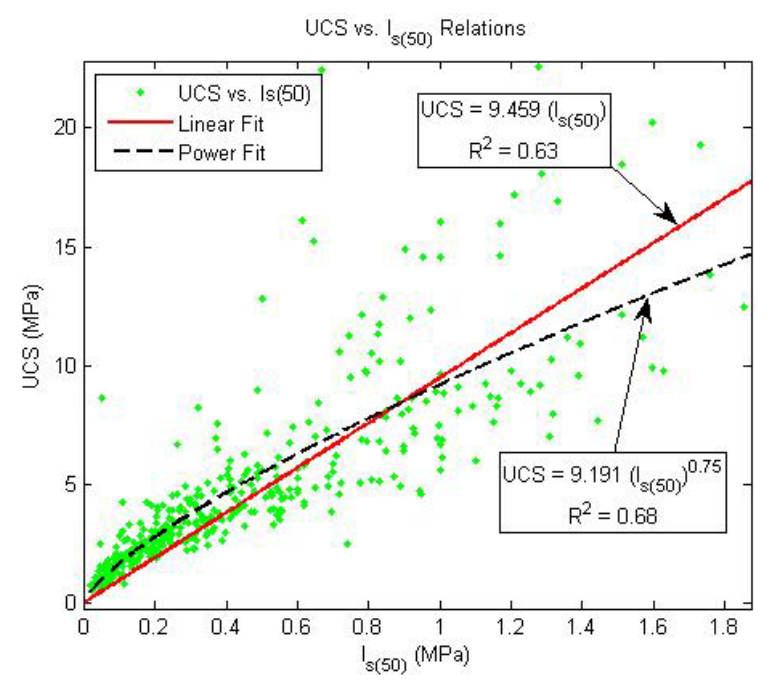

Figure 4. All rock types and strengths, (AA).

Table 2. Statistical summary of test results.

\begin{tabular}{ccc}
\hline Statistic & Point Load Strength Index $\mathbf{I}_{\mathbf{s}(\mathbf{5 0})}(\mathbf{M P a})$ & UCS $(\mathbf{M P a})$ \\
\hline Minimum & 0.017 & 0.540 \\
Maximum & 1.856 & 22.606 \\
Mean & 0.434 & 4.614 \\
Standard Deviation & 0.386 & 3.756 \\
\hline
\end{tabular}




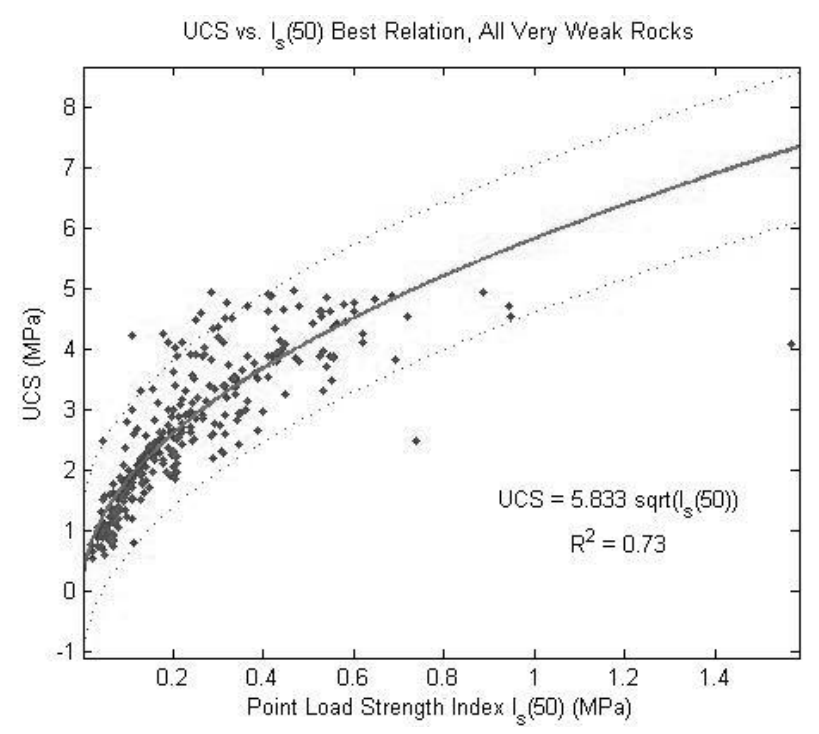

Figure 5. UCS vs. $\mathrm{I}_{\mathrm{S}(50)}$ relation, AV case.

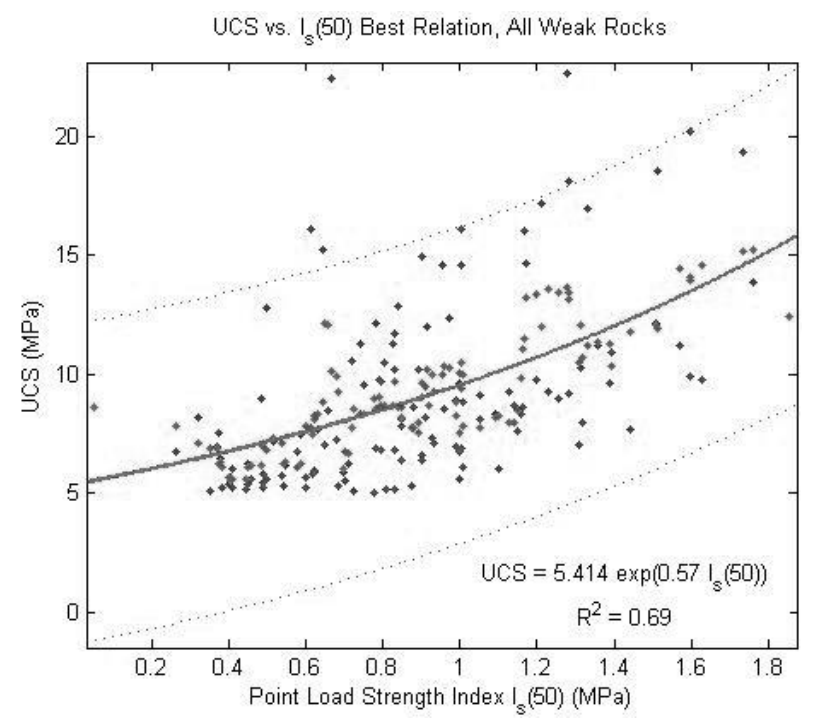

Figure 6. UCS vs. $\mathrm{I}_{\mathrm{S}(50)}$ relation, AW case.

Table 3. Summary of other relations between UCS and $\mathrm{I}_{\mathrm{s}(50)}(\mathrm{MPa})$.

\begin{tabular}{ccc}
\hline Case & Equation: $\mathbf{U C S}=$ & $\mathbf{R}^{\mathbf{2}}$ \\
\hline All types, very weak, (AV) & $5.833 \sqrt{\mathrm{I}_{\mathrm{s}(50)}}$ & 0.73 \\
All types, weak, (AW) & $5.414 \exp \left(0.57 \mathrm{I}_{\mathrm{s}(50)}\right)$ & 0.69 \\
All strengths Crystalline Gypsum, (CA) & $11.08 \mathrm{I}_{\mathrm{s}(50)}$ & 0.69 \\
Weak Crystalline Gypsum, (CW) & $11.24 \mathrm{I}_{\mathrm{s}(50)}$ & 0.55 \\
All strengths Mudstone, (MA) & $6.050 \sqrt{\mathrm{I}_{\mathrm{s}(50)}}$ & 0.71 \\
Very weak Mudstone, (MV) & $5.953 \sqrt{\mathrm{I}_{\mathrm{s}(50)}}$ & 0.7 \\
All strengths Sandstone, (SA) & $7.701 \mathrm{I}_{\mathrm{s}(50)}$ & 0.72 \\
Very weak Sandstone, (SV) & $5.679 \sqrt{\mathrm{I}_{\mathrm{s}(50)}}$ & 0.8 \\
Weak Sandstone, (SW) & $8.170 \sqrt{\mathrm{I}_{\mathrm{s}(50)}}$ & 0.44 \\
\hline
\end{tabular}




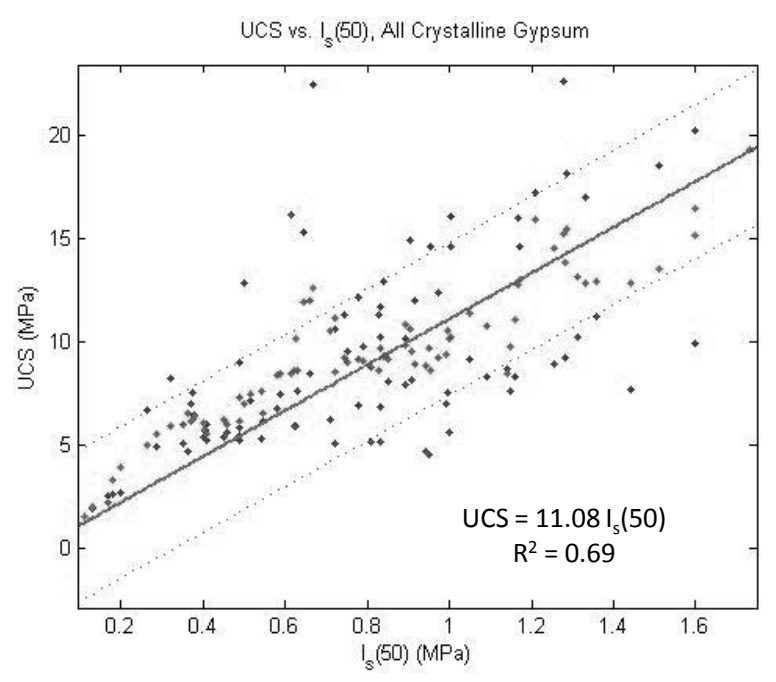

Figure 7. UCS vs. $\mathrm{I}_{\mathrm{S}(50)}$ relation, CA case.

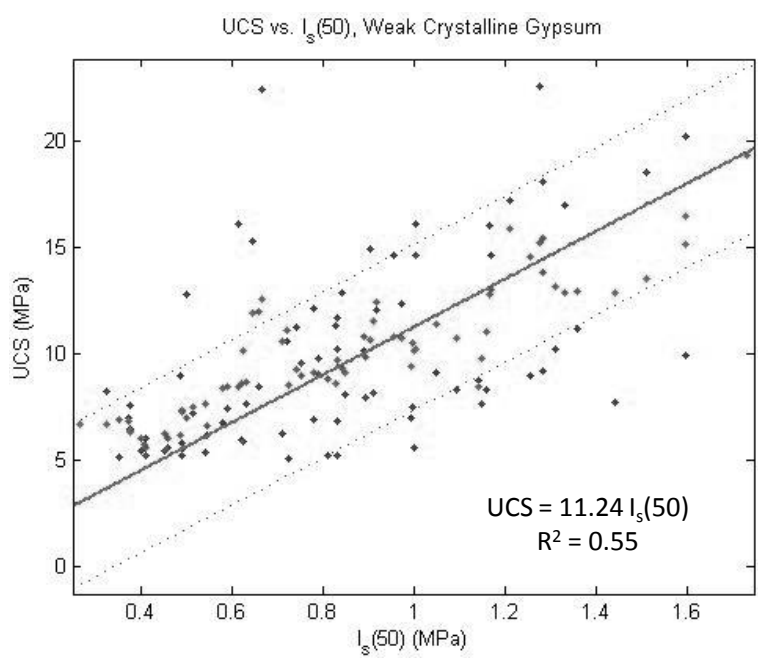

Figure 8. UCS vs. $\mathrm{I}_{\mathrm{S}(50)}$ relation, $\mathrm{CW}$ case.

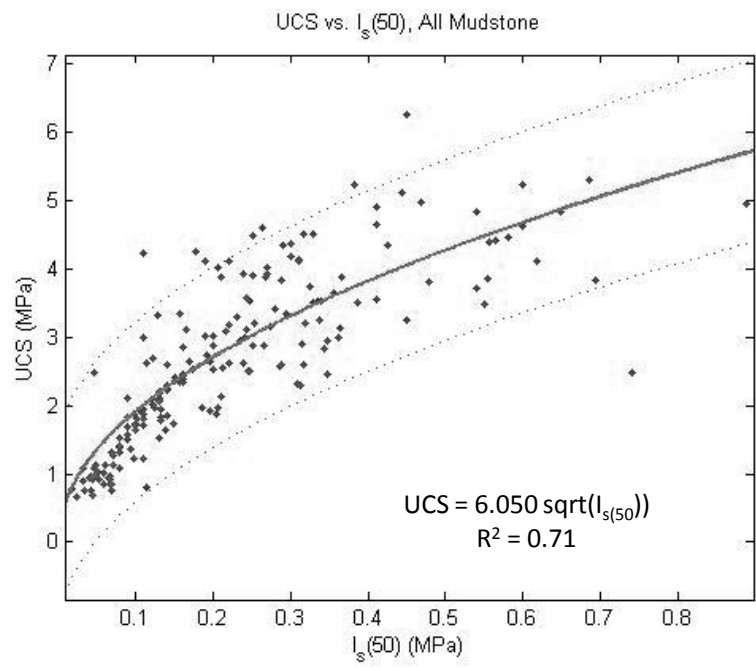

Figure 9. UCS vs. $\mathrm{I}_{\mathrm{S}(50)}$ relation, MA case. 


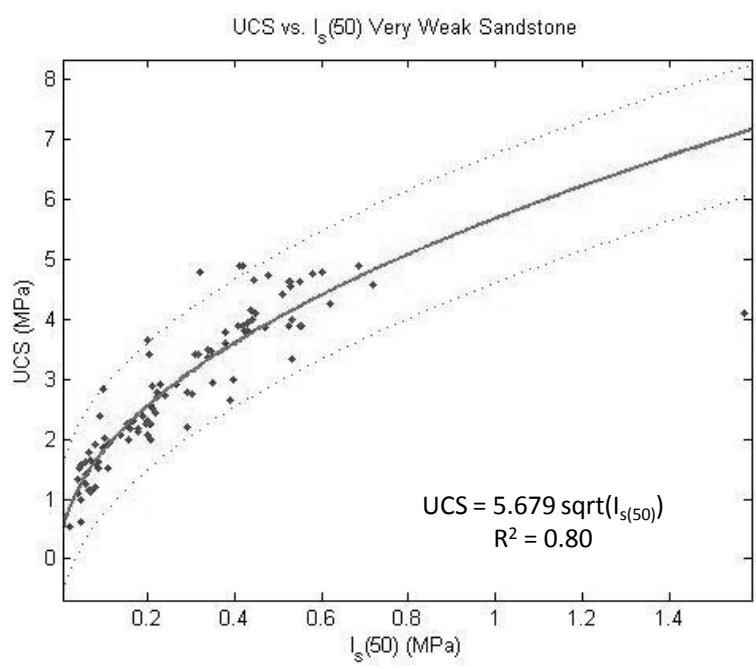

Figure 10. UCS vs. $\mathrm{I}_{\mathrm{S}(50)}$ relation, $\mathrm{SV}$ case.

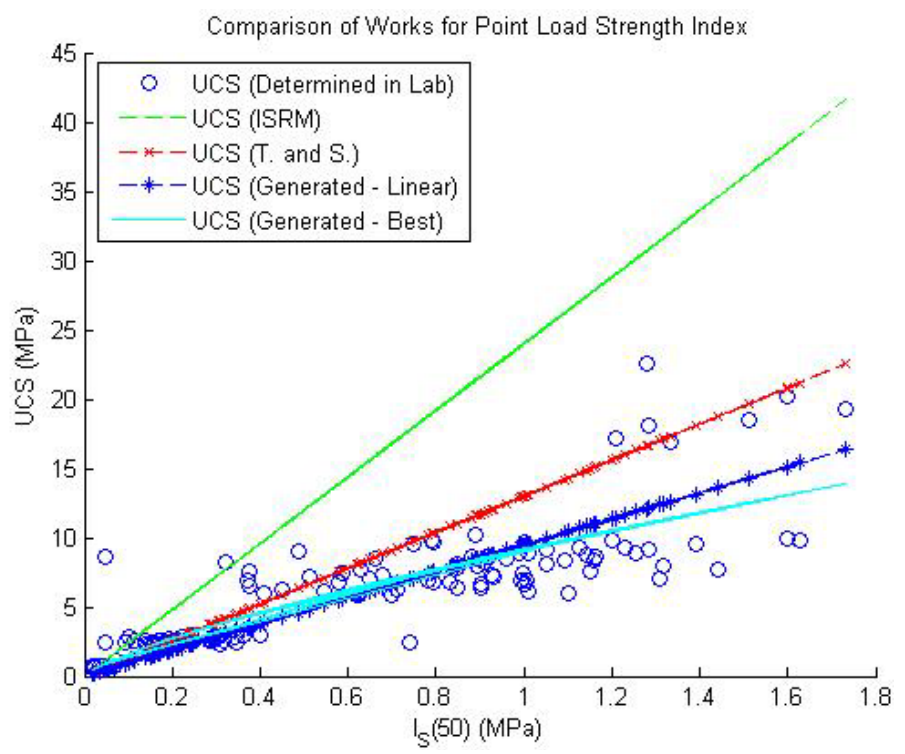

Figure 11. Comparison with other studies for point load strength index.

A critical review on the correlations shows that generated relationships in this study and Tsiambaos and Sabatakakis can predict UCS much better than correlation proposed by ASTM/ISRM for UAE rocks as it gives more of a conservative design values. In fact, in comparison to the observed UCS.

\section{Conclusion}

Four hundred nineteen rock samples from various areas along the coastal region of the UAE were collected and tested for the development of this dataset and evaluation of models. From the statistical analysis of the data, regression equations were established among rock parameters and correlations were expressed and compared by the ones proposed in literature. Through a critical review on some recent correlations for UCS prediction, it was observed that generated relationships for UAE rocks and those from Tsiambaos and Sabatakakis can predict UCS much better than correlation proposed by ASTM/ISRM as it gives more of a conservative design values.

\section{References}

[1] Tsiambaos, G. and Sabatakakis, N. (2004) Considerations on Strength of Intact Sedimentary Rocks. Engineering Ge- 
ology, 72, 261-273. http://dx.doi.org/10.1016/j.enggeo.2003.10.001

[2] American Society of Testing and Materials (ASTM) (2008) Standard Test Method for Determination of the Point Load Strength Index of Rock and Application to Rock Strength Classifications, D5731-08.

[3] Broch, E. and Franklin, J. (1972) International Journal of Rock Mechanics and Mining Sciences, 9, 669-697.

[4] D'Andrea, D.V., Fischer, R.L. and Fogelson, D.E. US Department of the Interior, Bureau of Mines, Report of Investigations. 6702, 1-23.

[5] Jaeger, J., et al. (2007) Deformation and Failure of Rocks. Fundamentals of Rock Mechanics. 4th Edition, Blackwell Publishing, 80.

[6] American Society of Testing and Materials (ASTM) (2002) Standard Test Method for Unconfined Compressive Strength of Intact Rock Core Specimens, D2938-95(R02).

[7] American Society of Testing and Materials (ASTM) (2008) Standard Practices for Preparing Rock Core as Cylindrical Test Specimens and Verifying Conformance to Dimensional and Shape Tolerances, D4543-08.

[8] American Society of Testing and Materials (ASTM) (2010) Standard Test Method for Compressive Strength and Elastic Moduli of Intact Rock Core Specimens under Varying States of Stress and Temperatures, D7012-10. 